\title{
The Organization of the Motoneurons Innervating the Axial Musculature of Vertebrates. II. Florida Water Snakes (Nerodia fasciata pictiventris)
}

\author{
JOSEPH R. FETCHO
}

Division of Biological Sciences, the University of Michigan, Ann Arbor, Michigan 48109

\begin{abstract}
The motor pools of axial muscles in Florida water snakes (Nerodia fasciata pictiventris) were studied by applying horseradish peroxidase (HRP) to branches of spinal nerves innervating individual muscles or groups of muscles. Motor pools of different muscles or muscle groups were located in characteristic positions in both the transverse and the longitudinal extent of the motor column. Epaxial pools were located ventromedially in the column, segregated from most hypaxial ones, which were dorsolateral. The only exception to this general rule was the motoneurons innervating the levator costae muscle. Some of the motoneurons innervating this hypaxial muscle were located in the ventral part of the motor column, like epaxial motoneurons, but they were segregated longitudinally from epaxial ones.

The arrangement of the motor pools was strikingly similar to the motor pools of presumptive homologous muscles in rats (Smith and Hollyday: $J$. Comp. Neurol. 220:29-43, '83), even though the locomotor mechanics in the two animals are very different. The similarities may reflect a comparable relationship between the location of motoneurons in the motor column and the location, in embryonic life, of the muscles they innervate. They also suggest that differences in the locomotor mechanics in the two species are accomplished without any dramatic reorganization of the medial motor column, in marked contrast to the substantial reorganization necessary to account for differences in the motor columns of amniotes and anamniotes.
\end{abstract}

Key words: spinal nerves, motor pools, somatotopy, locomotion, afferents

\begin{abstract}
The axial musculature of vertebrates shows a remarkable range of anatomical variation, from the relatively simple myomeric musculature in many anamniotic vertebrates to the intricate arrangement of the many muscles present in limbless amniotic vertebrates. All of the different muscular arrangements are derivatives of a primitive myomeric organization. One important aspect of understanding the motor systems of vertebrates involves learning about the changes in the central nervous system that may have accompanied the anatomical and functional reorganization of the musculature.
\end{abstract}

The previous paper (Fetcho, '86) dealt with motoneurons innervating axial musculature in two species of aquatic anamniotic vertebrates with relatively undifferentiated axial musculature. In this paper, I consider the motoneurons innervating axial musculature in a limbless semi-aquatic amniote, a snake (Nerodia fasciata pictiventris). The snakes, amphisbaenids, and limbless lizards rely solely upon axial muscles for locomotion, and their muscles are the most anatomically complex of all vertebrates (Gasc, '81). In snakes, the muscles are arranged segmentally, but in other respects the musculature differs substantially from the primitive myomeric organization. Each spinal nerve innervates many discrete muscles that often span several body segments (Gasc, '81; Jayne, '82). This remarkably complex

\footnotetext{
Accepted February 14, 1986.

J.R. Fetcho's present address is the Division of Neurobiology, Department of Physiology, SUNY at Buffalo, Buffalo, NY 14214.
} 
musculature is dramatically different from that in anamniotic vertebrates. I have used HRP to examine how the motor pools of this musculature are organized in the spinal cord and how their organization compares with the organization of the medial motor column in other vertebrates.

\section{MATERIALS AND METHODS}

Florida water snakes (Nerodia fasciata pictiventris) collected from the wild were obtained commercially from The Shed (a reptile dealer in Miami, Florida). They were maintained at room temperature in plastic boxes $(330 \times 250 \times$ $90 \mathrm{~mm}$ ) and were fed whole smelt. Six animals were used for gross anatomical study, and 11 animals having snoutvent lengths ranging from 400 to $690 \mathrm{~mm}$ were used for 39 experiments in which motoneurons were successfully filled by HRP applied to branches of spinal nerves. The snakes were anesthetized with sodium pentobarbital $(30 \mathrm{mg} / \mathrm{kg}$ body weight), and all surgical procedures, including sacrifice, were performed while they were anesthetized.

\section{HRP-labeling experiments}

In all of the labeling experiments, HRP was applied to isolated proximal ends of transected branches of spinal nerves innervating individual axial muscles or groups of muscles. Nerves, rather than muscles, were labeled because many of the muscles are small and thin, and those from successive body segments often overlap extensively. Consequently, it would be very difficult to selectively label motoneurons innervating individual muscles by injecting HRP into the muscles. Also, problems with leakage of HRP were experienced in all previous studies of the motor pools of axial muscles in amniotes (Brink et al., '79; Richmond et al., '78; Smith and Hollyday, '83). Isolated nerves were labeled to avoid these problems.

To label nerves, the snakes were anesthetized; a nerve was exposed, transected, and the proximal end was placed into a well made from a small piece of polyethylene tubing with one end sealed. A pledget of Gelfoam soaked in a $30-$ $50 \%$ solution of HRP in snake Ringer's (Ridge, '71) was placed in the well, on the end of the nerve, and the well was covered with petroleum jelly. With the dosage of anesthetic used, the snakes were anesthetized and immobile for 15-20 hours. Consequently, the nerves reliably remained in the well with the HRP for many hours. Nerves were exposed to HRP for at least 10 hours; then they were removed from the well, the area was rinsed with Ringer's, and the opening in the skin was sutured shut.

After 1-2 weeks survival, the snakes were anesthetized and perfused, first with Ringer's, and then with phosphatebuffered $4 \%$ glutaraldehyde. The spinal cord was exposed by laminectomy and fixed in situ for 1-2 hours with $4 \%$ glutaraldehyde. Pieces of cord containing the ventral root of the labeled segment and one and one-half segments on each side of the root were removed, fixed for an additional $2-4$ hours, and then placed in $30 \%$ sucrose in phosphate buffer until they were processed for HRP.

\section{Processing for HRP}

The spinal cords were embedded, sectioned at $40 \mu \mathrm{m}$, and processed for HRP by using the diaminobenzidine reaction, as described in the preceding paper.

In control experiments, spinal cords from regions of the body not exposed to HRP, or from segments containing a nerve branch exposed to Ringer's alone, were treated for peroxidase. In these experiments, reaction product was associated with those few blood cells remaining after perfu- sion; however, no reaction product was associated with motoneurons. I conclude that the motoneurons did not have endogeneous peroxidase activity.

\section{Reconstruction of the locations of motoneurons}

The locations of motoneurons were reconstructed with the aid of a camera lucida by tracing successive sections of spinal cords onto transparent sheets of polyester. The locations of the central canal, the midline of the cord, the outline of the ventral horn, and the positions of HRP-filled motoneurons and possible unlabeled motoneurons (relatively large cells in the ventral horn, and not containing reaction product) were plotted on the tracings. Summary sections representing the distribution of labeled cells in the transverse extent of the ventral horn were made by superimposing a series of sections onto a representative section from within the series.

\section{RESULTS Musculature and innervation}

The axial muscles in snakes have been described by others (Mosauer, '35; Auffenberg, '61, '62; Jayne, '82; Gasc, '81). The details of the very complex musculature are not considered here. Instead, I summarize those features necessary for understanding the relationships between motor pools and muscles.

The muscles and their innervation were examined by dissection with the aid of a dissecting microscope. Approximately 25 different muscles are innervated by each spinal nerve on one side of the trunk. The musculature is not myomeric, but it is serially repeated. That is, the same 50 muscles ( 25 on each side) are present in each body segment, and they form a rostrocaudal series of nearly identical repeated units. Their names and their abbreviations are listed in Table 1. I use the nomenclature provided by Gasc ('81); where it differs from that used by Mosauer ('35), I have provided Mosauer's names in parentheses. A few of the smaller, deep muscles, whose motor nuclei were not mapped, are not listed in Table 1 . These include the $M$. multifidus, the $M$. interarticularis superior partes dorsalis et ventralis ( $M$. digastricus), the $M$. interarticularis inferior, the $M$. costovertebrocostalis, the $M$. tuberculocostalis, and the $M$. intertransversarius. All of these are relatively small, and together they account for a small fraction (easily less than 10 percent) of the total volume of the axial musculature.

Figure 1 shows the major muscles and their innervation in a diagrammatic cross section through the body of a water snake. Dorsal and ventral roots exit from the spinal cord and join at a spinal ganglion. Dorsal (DR) and ventral (VR) rami (Fig. 1) arise from the ganglion and run peripherally to innervate the muscles and the skin. The axial muscles in amniotes are usually divided into epaxial and hypaxial groups based upon whether they are innervated by branches of the dorsal or ventral rami of a spinal nerve, respectively (Romer and Parsons, '77; Northcutt, '79; Gasc, '81). I follow this convention below.

The dorsal ramus innervates the three main groups of epaxial muscles, which lie on the dorsolateral side of the vertebrae and ribs (Fig. 1). They are, from dorsal to ventral, the semispinalis-spinalis (ss), longissimus (1), and iliocostalis (i). Three similar groups are found in most other reptiles and in mammals (Nishi, '38; Gasc, '81; Smith and Hollyday, '83). In snakes, these muscles attach vertebrae to other vertebrae or attach vertebrae to the ribs. All of these muscles span many body segments (for example, there are 
TABLE 1. Nerve/Muscle Names, Abbreviations, and Number of Experiments

\begin{tabular}{|c|c|c|}
\hline Nerve branch & Abbreviation & $\begin{array}{l}\text { No. of } \\
\text { experiments }\end{array}$ \\
\hline \multicolumn{3}{|l|}{ Dorsal ramus } \\
\hline \multicolumn{3}{|l|}{ Medial branch } \\
\hline (M. semispinalis-M.spinalis) & ss & 5 \\
\hline Lateral branch & & 2 \\
\hline M. longissimus dorsi & 1 & 4 \\
\hline M. iliocostalis & $\mathrm{i}$ & 6 \\
\hline \multicolumn{3}{|l|}{ Ventral ramus } \\
\hline Medial branch & VRm & 5 \\
\hline$M$. transversus dorsalis & td & \\
\hline $\begin{array}{l}\text { M. obliquus internus pars dorsalis } \\
\text { (M. costalis internus superior) }\end{array}$ & oid & \\
\hline Posterior portion & VRmp & 4 \\
\hline $\begin{array}{l}\text { M. transversus ventralis } \\
\quad(M . \text { transuersus abdominus })\end{array}$ & tv & \\
\hline $\begin{array}{l}\text { M. obliquus internus pars ventralis } \\
(M \text {. costalis internus inferior })\end{array}$ & oiv & \\
\hline (M. obliquus abdominus internus) & oai & \\
\hline $\begin{array}{l}\text { M. costocutaneous inferior } \\
\text { ventral cutaneous muscles }\end{array}$ & $\begin{array}{l}\text { cci } \\
\text { vc }\end{array}$ & \\
\hline $\begin{array}{l}M . \text { intercostalis externus } \\
(M . \text { intercostalis proprius })\end{array}$ & ie & \\
\hline M. supracostalis lateralis inferior & sli & \\
\hline $\begin{array}{l}M . \text { intercostalis ventralis } \\
\quad(M . \text { intercartilaginosus })\end{array}$ & iv & \\
\hline Anterior portion & VRma & 6 \\
\hline M. costocutaneous superior & $\operatorname{ces}$ & \\
\hline lateral cutaneous muscles & $\mathrm{lcm}$ & \\
\hline \multicolumn{3}{|l|}{ Lateral branch } \\
\hline Posterior portion & VRlp & 3 \\
\hline M. intercostalis quadrangularis & iq & \\
\hline M. supracostalis lateralis superior & sls & \\
\hline \multicolumn{3}{|l|}{ Anterior portion } \\
\hline M. levator costae & lc & 4 \\
\hline
\end{tabular}

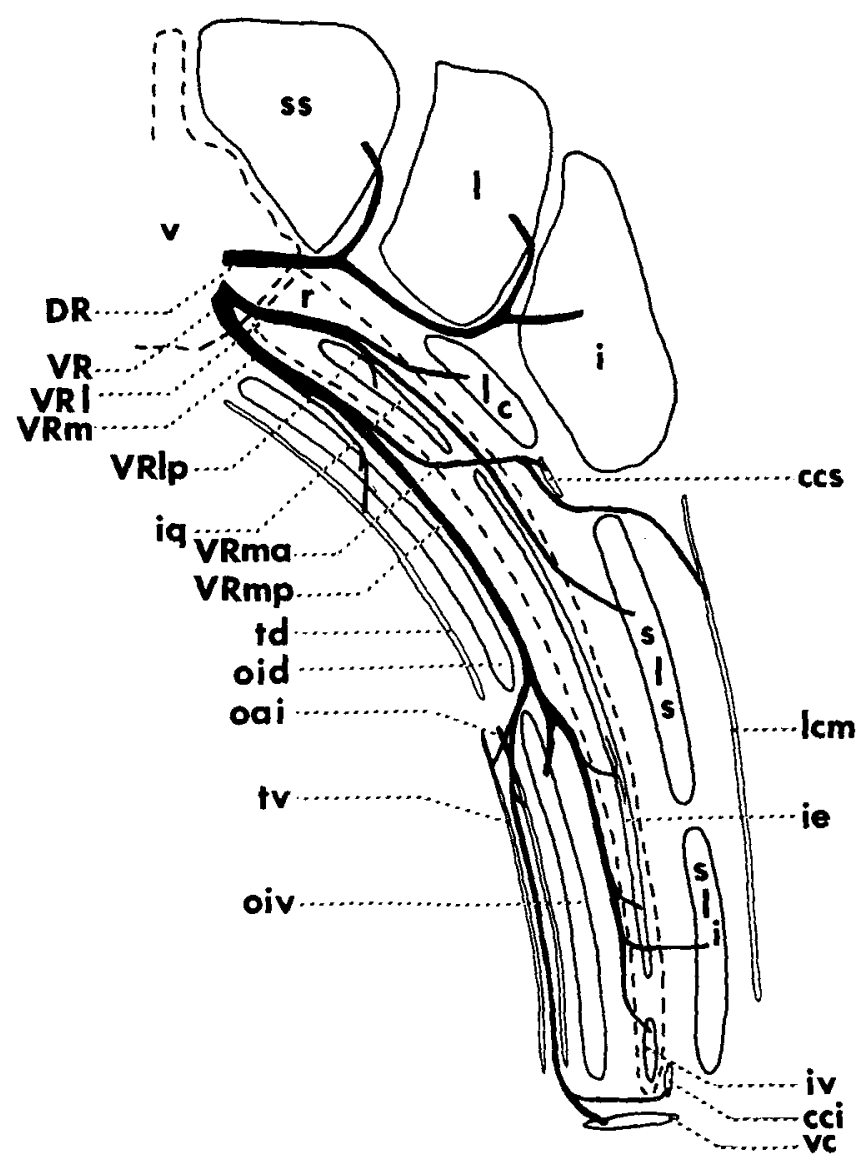

20 between the origin and insertion of the spinalis muscle, Jayne, '82), and those from successive segments overlap one another. The dorsal ramus also innervates some smaller deep dorsal muscles (e.g., $M$. multifidus, $M$. interarticularis superior partes dorsalis et ventralis), and the skin on the dorsolateral side of the body.

The ventral ramus innervates both the hypaxial muscles associated with the ribs and the skin and intrinsic muscles of the skin on the ventral and ventrolateral sides of the body. I somewhat arbitrarily divide these muscles into three groups based on their positions relative to the ribs: lateral, intercostal, and medial.

The lateral group lies on the external side of the ribs. It includes the lateral cutaneous muscles $(1 \mathrm{~cm})$, which are small intrinsic muscles of the skin; the thin costocutaneous muscles (superior (ccs) and inferior (cci)), which connect the ribs to the skin; the supracostalis lateralis muscles (superior (sls) and inferior (sli)), reasonably stout muscles that originate on a rib, and run caudally, crossing over the lateral surface of several ribs to insert on more caudal ribs; and the levator costae muscles (lc), short stout muscles that

Fig. 1. Diagrammatic hemisection through the trunk of Nerodia showing the major muscle groups and the branching pattern of the spinal nerves innervating them. The vertebra and rib are outlined by dotted lines, the muscles are outlined by solid lines, and the nerve branches are solid black. A simplified version of this figure, showing only the branching pattern of nerves, is used to indicate the nerve labeled with HRP in subsequent figures illustrating motor pool reconstructions. The abbreviations of muscles are summarized in Table 1. A few of the small deeper muscles whose motor pools were not mapped (see Results) are not shown in this figure. $v$, vertebra; $r$, rib; DR, dorsal ramus of a spinal nerve; VR, ventral ramus of a spinal nerve; VRI, lateral branch of VR; VRm, medial branch of VR; VRlp, posterior portion of VRl; VRma, anterior portion of VRm; VRmp, posterior portion of VRm. 
originate from a vertebra and insert on the dorsal part of the rib articulating with the next caudal vertebra.

The intercostal group of muscles interconnects adjacent ribs. It includes, from dorsal to ventral, the intercostalis quadrangularis (iq), the intercostalis externus (ie), and the intercostalis ventralis (iv).

The medial group of muscles lies on the internal side of the ribs. The obliquus internus muscles (pars dorsalis (oid), and ventralis (oiv)) lie closest to the ribs. They originate and insert on nonadjacent ribs, crossing the medial side of several ribs between those forming the origin and insertion. The transversus muscles (pars dorsalis (td), and ventralis (tv)) are very thin muscles lining the medial surface of the body wall just outside the peritoneum. The transversus dorsalis connects the ventral surface of the vertebrae to the ribs, while the transversus ventralis connects the ribs, via an aponeurosis, to the midventral skin. The obliquus abdominus internus (oai) is a thin muscle closely associated with the transversus ventralis.

Cutaneous muscles (vc) connect successive ventral scales, and these do not easily fall into one of the three groups of hypaxial muscles.

\section{Motor pools}

General comments. The motor pools were mapped by applying HRP to different branches of spinal nerves (see Methods). Branches of the dorsal ramus were labeled by entering the musculature through the skin on the dorsolat eral side of the body; branches of the ventral ramus were labeled by opening the body cavity and approaching the nerves from the inside of the body wall. The numbers of each type of labeling experiment are listed in Table 1. All of the nerves were labeled distal to the origin of the visceral ramus from the spinal nerve, to avoid filling preganglionic autonomic cells. Branches of spinal nerves entered nearby muscles, without extending many segments rostrally or caudally. Usually only a single branch of a spinal nerve from one body segment entered each muscle. This suggests that each muscle receives its innervation from a single spinal nerve, though some recent, more detailed, observations indicate that muscles may be innervated by more than one spinal nerve in regions where adjacent muscles contact one another (Lichtman et al., '85). Another possible exception to a strictly segmental innervation is the nerve supply of the iliocostalis muscle. The nerves innervating these muscles in adjacent segments joined one another to form a plexus, and branches arising from the plexus entered individual muscles. Iliocostalis motoneurons were filled by labeling a nerve proximal to its entry into the plexus.

My anatomical observations and previous observations by others (Mosauer, '35; Jayne, '82) indicated that over much of the body of snakes the musculature consists of a series of nearly identical repeated segments. There are approximately 125 segments along the trunk of Nerodia fasciata pictiventris; the exact number varies from animal to animal, ranging from 121 to 131 (Wright and Wright, '57). The motoneurons filled from a spinal nerve in one of these segments were always located less than one segment rostral or caudal to the place where the nerve exposed to HRP exited from the spinal cord. This narrow longitudinal distribution of cells filled from one spinal nerve, and the segmental arrangement of muscles made it feasible to label a number of nerves from different segments in a single animal; consequently, only a relatively small number of animals were killed.
When nerves from more than one body segment were labeled in an individual animal, two segments were skipped between each labeled nerve. With this spacing, the motoneurons labeled in different segments did not overlap along the rostrocaudal axis of the cord; therefore, HRP-filled motoneurons were easily and unambiguousily associated with a particular Iabeled nerve. The branches of spinal nerves labeled in this study were located along the main portion of the trunk, from approximately segment 50 to segment 80 .

In preliminary experiments, there were no contralateral labeled cells in the cords from animals in which nerves were exposed to HRP on only one side of the body. Therefore, in some animals nerves on both sides of the body were exposed to HRP, and in these, the labeled motoneurons were unambiguously associated with the ipsilateral labeled nerve.

General features of the spinal cord and motoneurons. Figure 2D shows one-half of a counterstained transverse section through the spinal cord of Nerodia. Asterisks outline the gray matter that forms well-defined dorsal and ventral horns in the central portion of the cord. The motoneurons, shown in Figures $2 \mathrm{C}$ and 3, were multipolar cells located in the ventral part of the ventral horn. Many of their dendrites extended laterally from the soma to the lateral edge of the ventral horn. Once there, they ran dorsally along the border between the ventral horn and the white matter, toward HRP-filled muscle afferents (Fig. 2A). Dendritic processes radiated laterally from the edge of the ventral horn well into the white matter (Fig. 2A,C). Some dendrites from motoneurons in the medial part of the ventral horn crossed to the contralateral side of the cord ventral to the central canal.

Motor pools of muscles innervated by the dorsal ramus. HRP was applied to the nerves innervating the three main groups of dorsal muscles (semispinalis-spinalis, longissimus, iliocostalis) supplied by the dorsal ramus. Figures $3 \mathrm{~A}$ and $\mathrm{B}$ show examples, in transverse sections, of motoneurons filled from the nerves innervating the semispinalis and iliocostalis muscles, respectively. Figure 4 shows representative reconstructions of the motor pools of all three groups. All of the motor pools were located in the ventromedial portion of the ventral horn. The semispinalisspinalis motoneurons occupied the medial edge of the ventral horn (Figs. 3A, 4A), and some of their dendrites crossed to the contralateral side of the cord ventral to the central canal (Fig. 3A). The motor pools of the longissimus and iliocostalis muscles occupied the ventral edge of the ventral horn, just lateral to the semispinalis-spinalis pool (Figs. 3B, $4 \mathrm{~B}, \mathrm{C})$. Although the locations of the iliocostalis and longissimus pools shown in Figure 4 differ slightly, these differ-

Fig. 2. The gross morphology of the cord and the distribution of afferents. All sections are cross sections, with a star placed in the central canal. A. A hemisection through a region where a dorsal root containing HRP-filled afferents enters the spinal cord. HRP was applied to the medial branch of the ventral ramus, which innervates both muscles and skin. The dorsal root afferents form two bundles within the cord (solid arrows). Open arrows indicate the dendrites of motoneurons. Bar $=100 \mu \mathrm{m}$. B. A higher-magnification view of the top portion of panel $A$ to show the afferents (arrows) ramifying in the dorsal and central portions of the dorsal horn. Bar $=50$ $\mu \mathrm{m}$. C. A cross section rostral to the piace where labeled axons in a dorsal root entered the spinal cord. The medial branch of the ventral ramus was labeled with HRP. The two groups of afferents (solid arrows) run longitudinally and are cut in cross section. Open arrows point to a group of HRPfilled motoneurons located ventrally. $\mathrm{Bar}=100 \mu \mathrm{m}$. D. Selective labeling of axons in only the ventrolateral group of afferents (arrows) by HRP applied to a nerve branch innervating only muscle. Asterisks outline the gray matter. dh, dorsal horn; vh, ventral horn. Bar $=100 \mu \mathrm{m}$. 

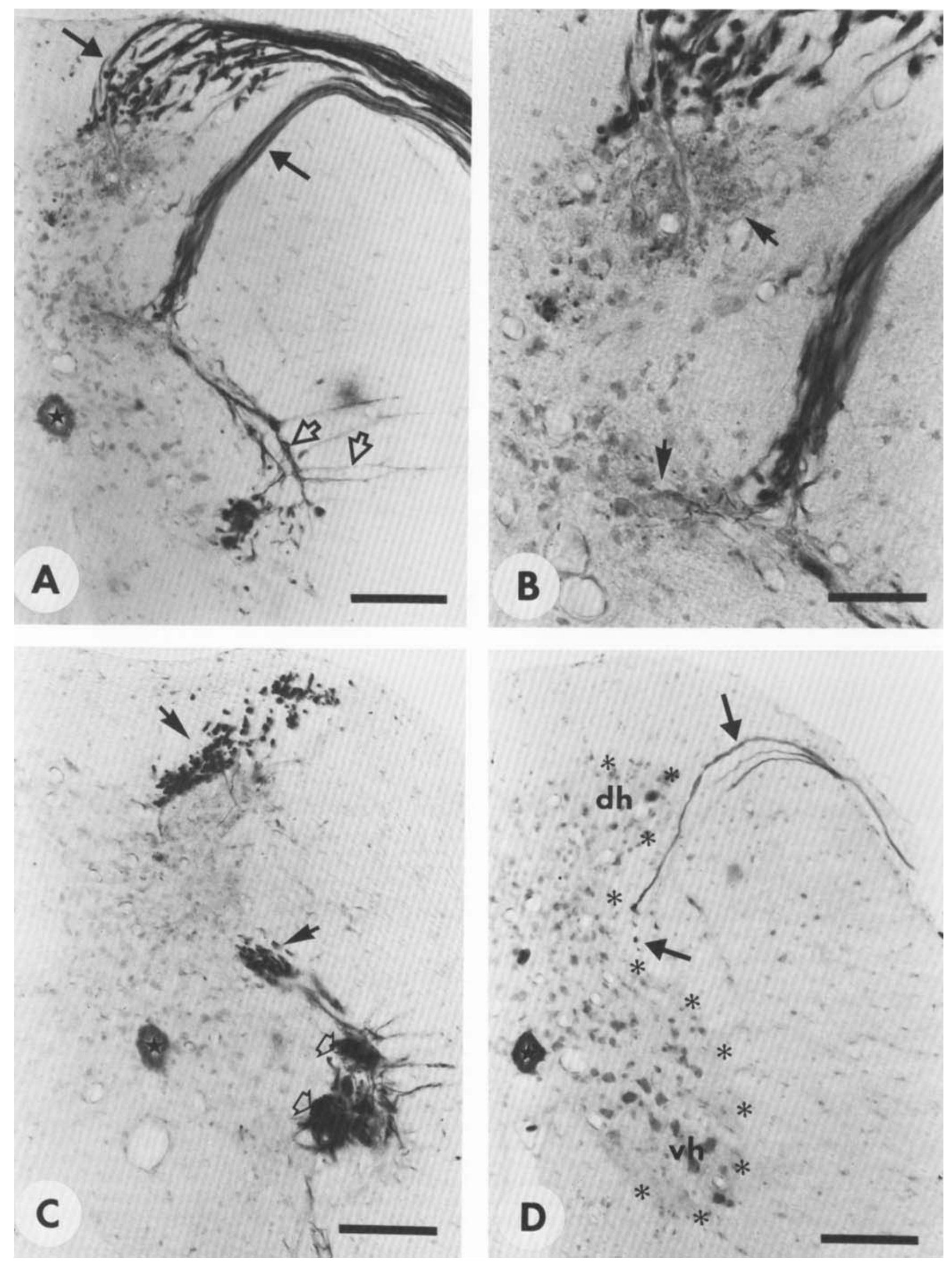

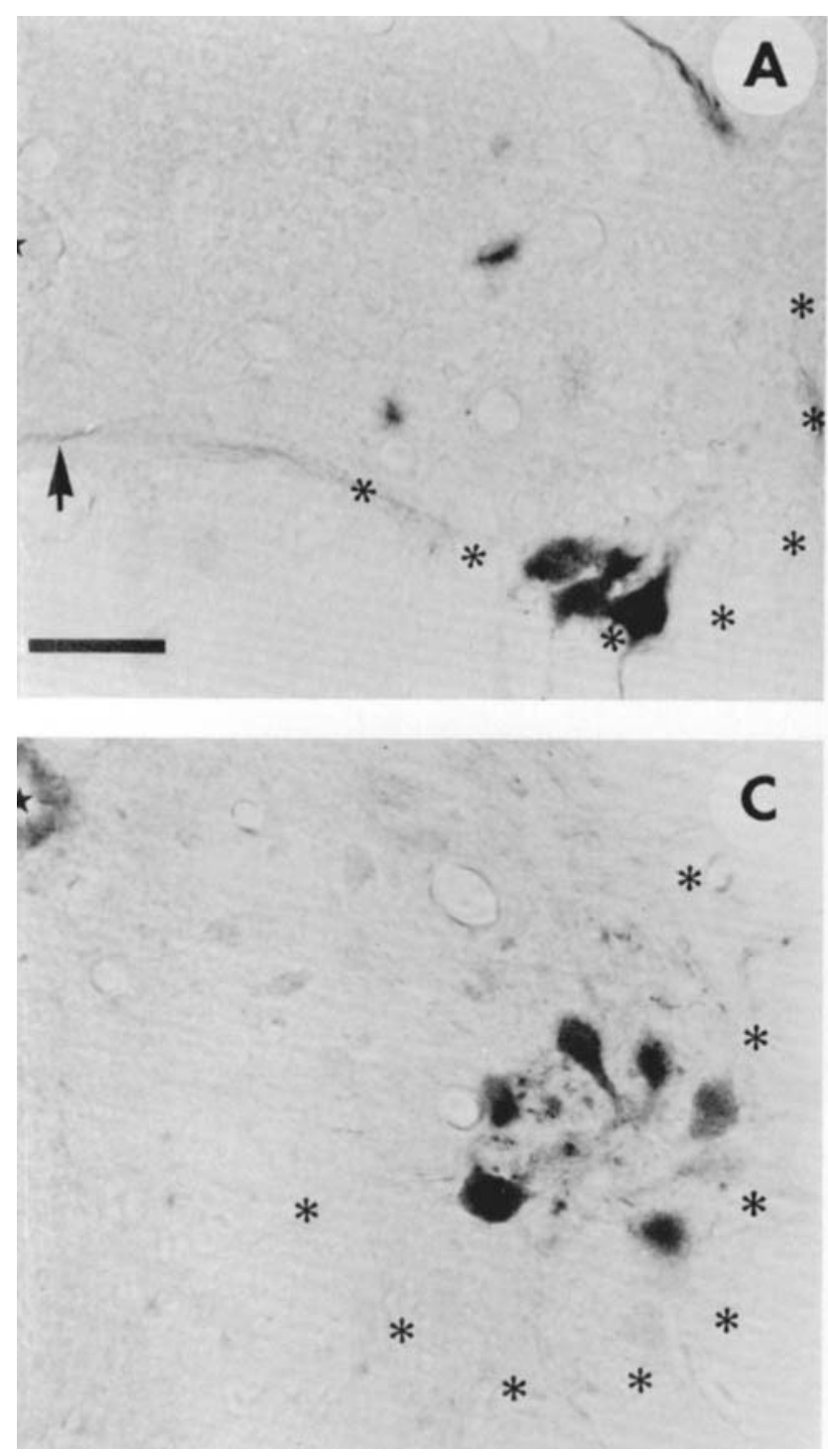

Fig. 3. HRP-filled motoneurons in the ventral horn of Nerodia. Cross sections of the spinal cord showing motoneurons in different regions of the ventral horn filled by HRP applied to branches of the dorsal ramus in $A$, semispinalis-spinalis and $B$, iliocostalis, or branches of the ventral ramus in $C$, posterior portion of the medial branch of the ventral ramus and $D$, anterior portion of the medial branch of the ventral ramus. A star is located

ences were not consistently present; the two usually overlapped, sometimes nearly completely.

The longitudinal distributions of the three motor pools overlapped (Fig. 4A1,B1,C1). All were located rostral to the labeled ventral root and extended from the root over approximately halfway to the next root.

Motor pools of muscles innervated by the ventral ramus. The ventral ramus has two major branches-a medial and a lateral one. The medial branch (VRm) innervates muscles in all three hypaxial groups (lateral, intercostal, and medial) associated with both the dorsal and ventral portions of the ribs (Fig. 1, Table 1). When the entire medial branch was exposed to HRP, motoneurons throughout the dorsolateral portion of the ventral horn were filled. Motoneurons from one of these experiments are shown in Figure
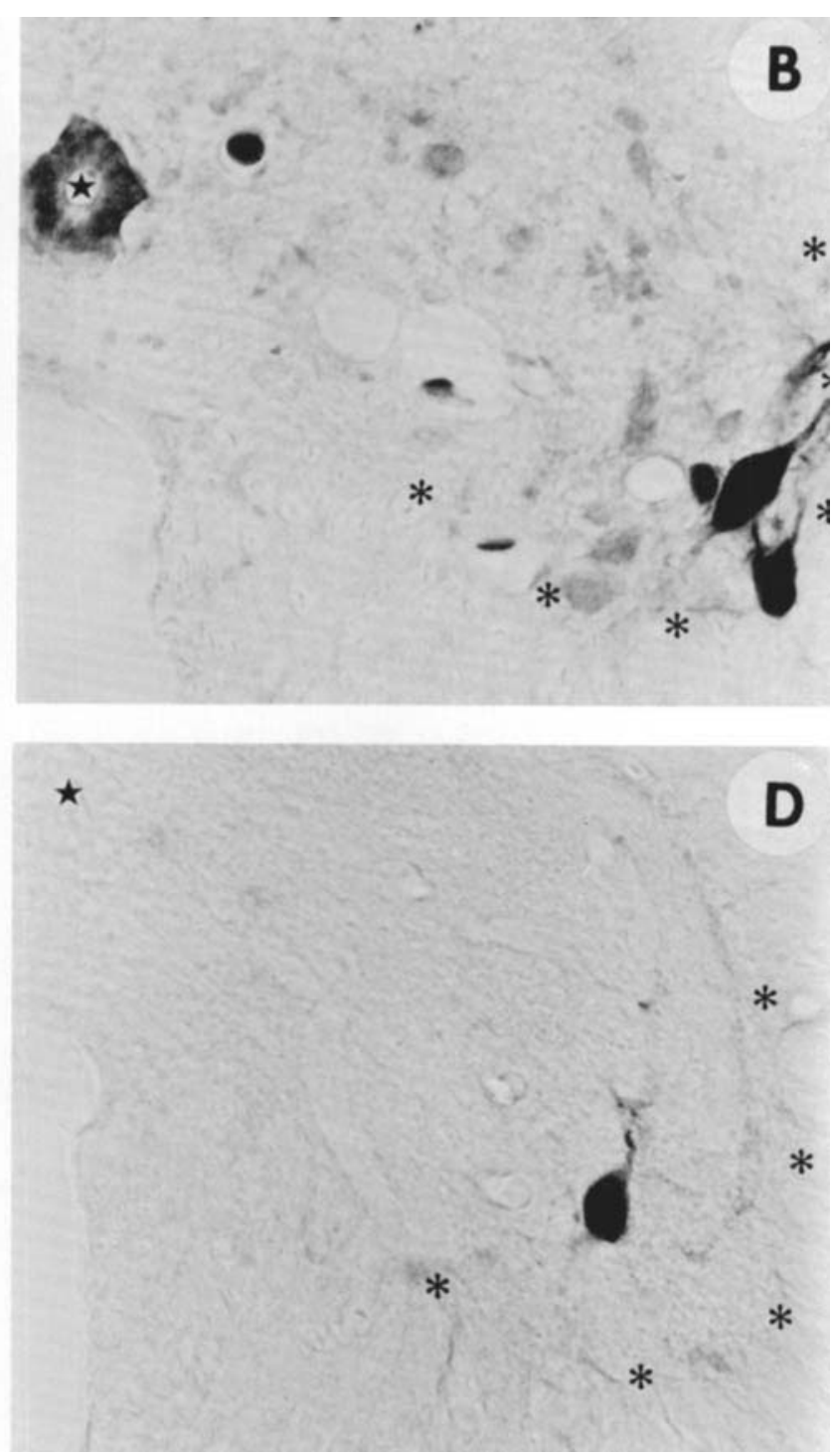

within the central canal, and asterisks outline the ventral portion of the ventral horn. The motoneurons labeled from the dorsal ramus ( $A$ and $B$ ) are located ventromedially in the ventral horn; those labeled from the ventral ramus $(C, D)$ are located dorsolaterally. Dendrites of some semispinalisspinalis motoneurons (arrow in A) cross to the contralateral side of the spinal cord. The bar in $\mathrm{A}=50 \mu \mathrm{m}$ and also applies to $\mathrm{B}, \mathrm{C}$, and $\mathrm{D}$.

$3 \mathrm{C}$, and a representative reconstruction is shown in Figure 5. The labeled motoneurons were distributed from the central region of the ventral horn, dorsolaterally to its lateral edge. They were located both rostral and caudal to the root containing the labeled branch, but the majority were al ways rostral to it (Fig. 5, bottom). Most of the more caudal ones were located centrally in the ventral horn (see the upper summary section in Fig. 5).

The medial branch breaks up into anterior and posterior portions. The posterior subdivision (VRmp) innervates muscles on the ventral portion of the ribs in all three layers of hypaxial muscles (Fig. 1). Motoneurons filled from this branch are shown in Figure 3C, and their distribution in one representative experiment is reconstructed in Figure $6 \mathrm{~A}$ and $\mathrm{A1}$. They had the same transverse and longitudinal 

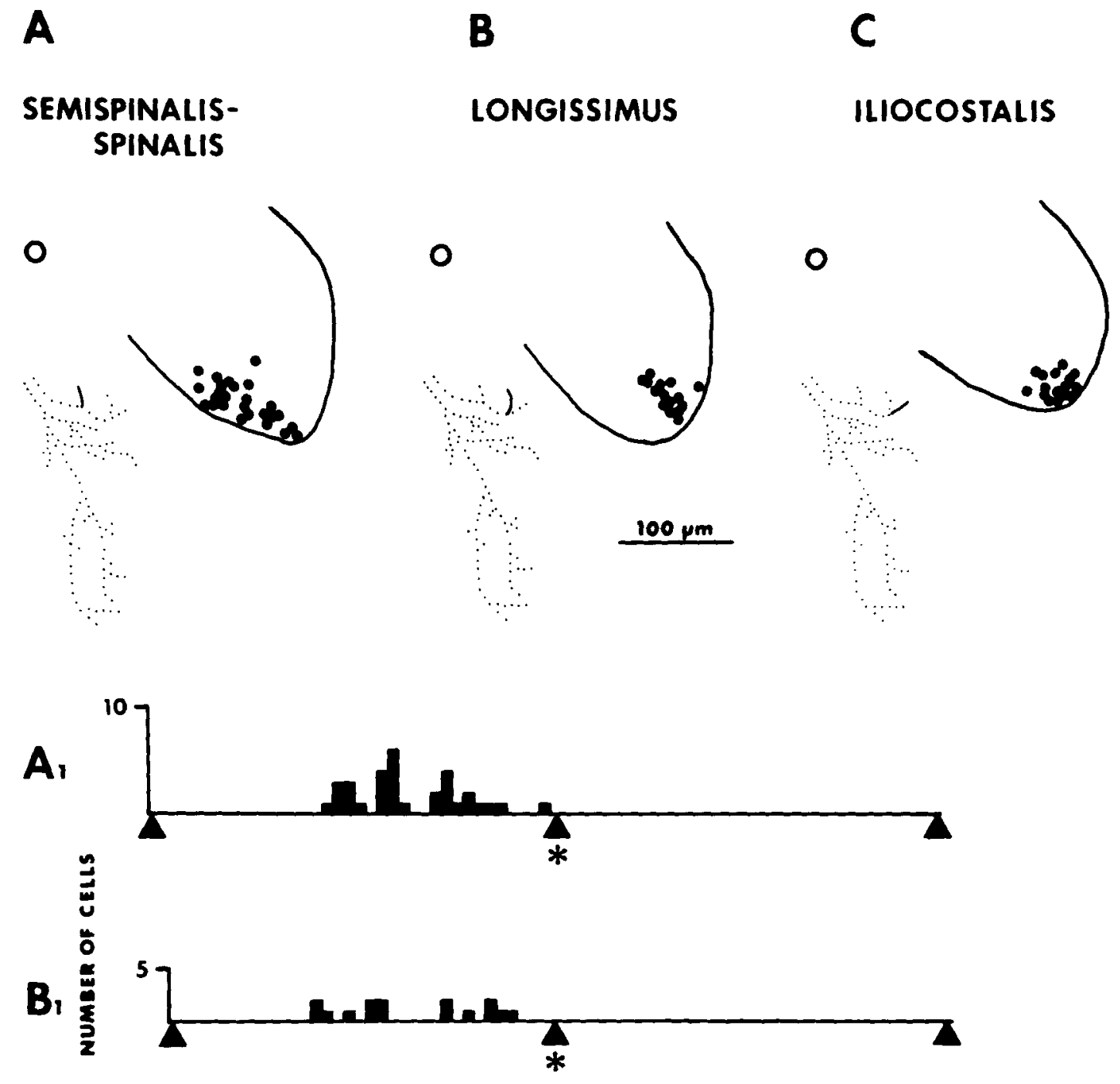

c

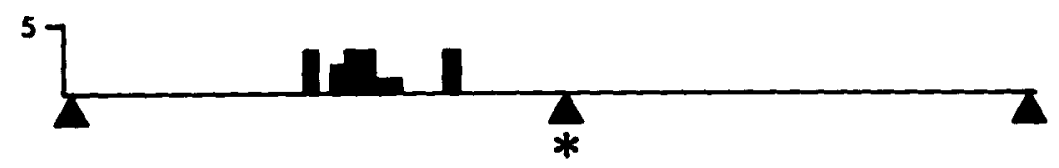

LONGITUDINAL DISTRIBUTION IN SPINAL CORD

orostrat

Fig. 4. Summary of the distribution of HRP.filled matoneurons in the ventral horn from representative experiments in which HRP was applied to branches of the dorsal ramus of a spinal nerve. $A, B$, and $C$ show the distribution, within the transverse extent of the ventral horn, of motoneurons innervating the semispinalis-spinalis, longissimus, and iliocostalis muscles. The central canal is indicated by a circle and the extent of the ventral horn is indicated by a solid line. The positions of labeled motoneurons are shown by solid black dots. Below each reconstruction is a simplified version of the spinal nerve branching pattern shown in Figure 1. On this, the nerve branch labeled with HRP in each experiment is indicated by a solid black line; the other, unlabeled branches, are shown as dotted lines. The histograms at the bottom of the figure (A1, B1, C1) show the longitudi-

distribution in the cord as those labeled from the entire medial branch of the ventral ramus.

The anterior subdivision of the medial branch of the ventral ramus (VRma) innervates muscles located on the lateral side of the ribs (Fig. 1). The motoneurons filled from nal distributions in the cord of the labeled cells from the experiments reconstructed in $\mathrm{A}, \mathrm{B}$, and $\mathrm{C}$. The triangles indicate the places where successive spinal nerves exit from the cord. The spinal nerve containing the labeled nerve branch in each experiment is marked with an asterisk. Each bin on the histograms represents the number of labeled cells in a distance of $80 \mu \mathrm{m}$ along the longitudinal axis of the cord. No corrections for shrinkage or estimating the number of cells were applied because the primary concern was the location of the labeled cells relative to the labeled root, not the exact number of filled cells. The distance between spinal nerves in different experiments varies because of variability in the size of animals. All subsequent figures showing reconstructions of motor pools are organized like this one, except where noted.

VRma were confined to the central part of the ventral horn and were evenly distributed rostral and caudal to the ventral root (Figs. 3D, 6B,B1).

The lateral branch of the ventral ramus (VRI) innervates dorsal hypaxial muscles in both the lateral and intercostal 


\section{VRm}

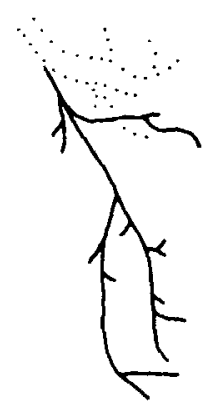

$\mathbf{O}$

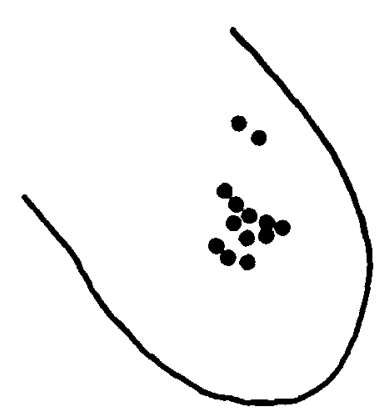

CAUDAL

$\mathbf{0}$

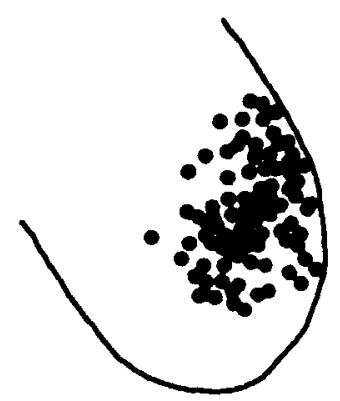

ROSTRAL

$100 \mathrm{pm}$

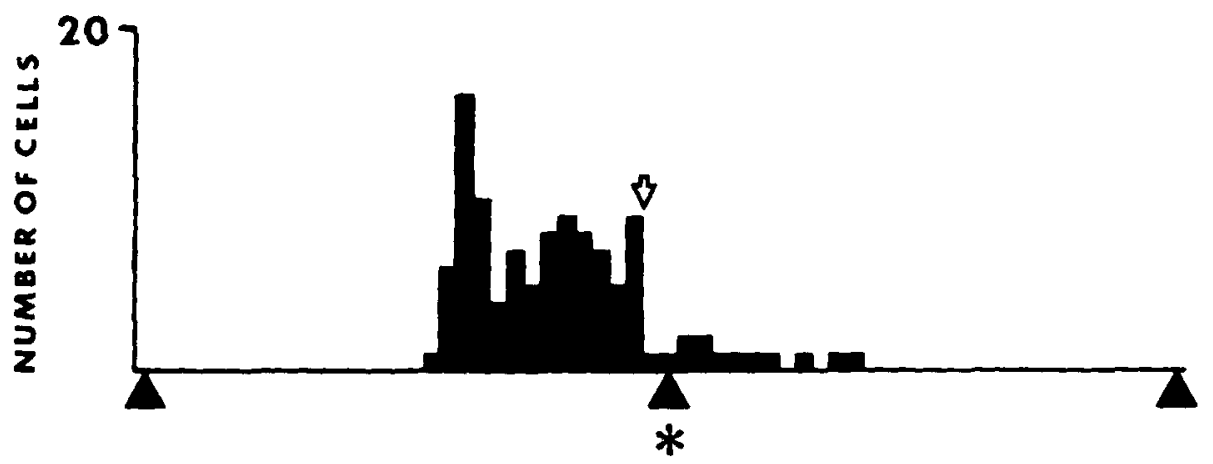

LONGITUDINAL DISTRIBUTION IN SPINAL CORO

\section{ROSTRAL}

Fig. 5. The distribution of HRP-filled motoneurons after applying HRP to the medial branch of the ventral ramus of a spinal nerve. The conventions are similar to those for Figure 4 , except, because of the large number of labeled cells, two summary transverse sections are shown. To produce these drawings, the number of sections between the most rostral and the most caudal labeled cells in the spinal cord was divided in half. Cells from the rostral half of the sections are plotted in the bottom summary section, while cells from the caudal half of the sections are plotted in the top summary section. The location of the split between rostral and caudal sections is indicated by an open arrow on the histogram showing the longitudinal distribution of the labeled cells. Each bin in the histogram represents a longitudinal distance of $80 \mu \mathrm{m}$ 
A
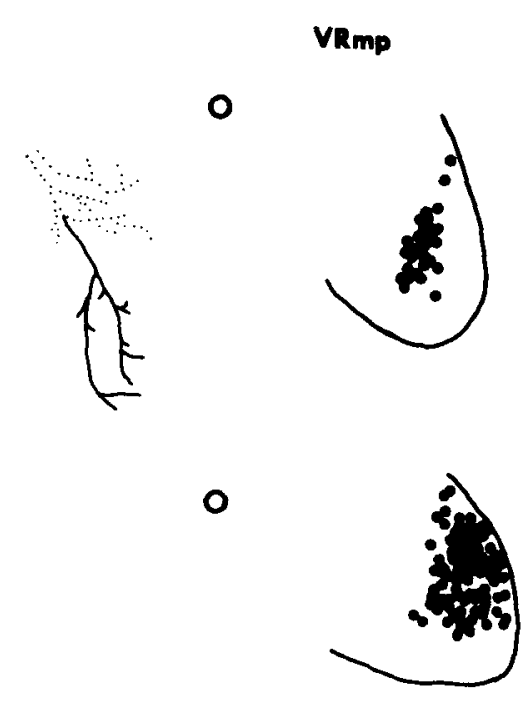

$$
\text { VRmp }
$$

0

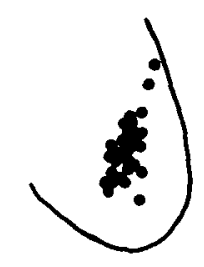

B

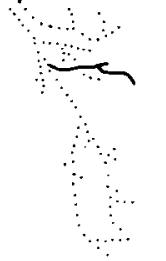

0

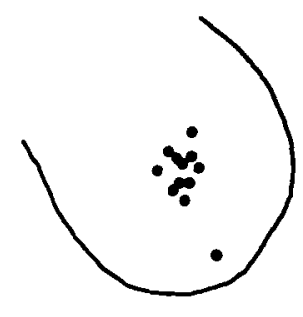

nostinal

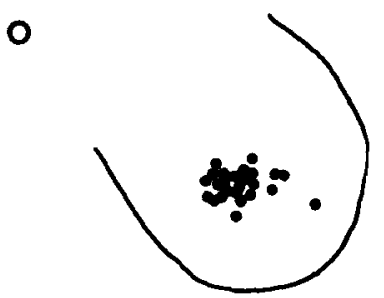

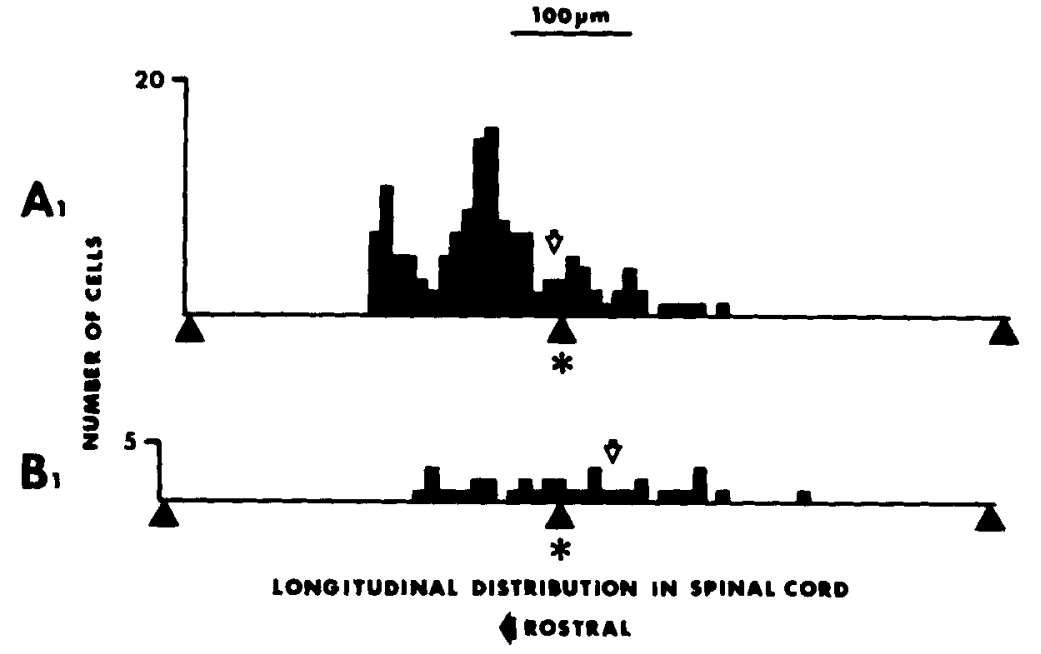

Fig. 6. The distribution of HRP-filled motoneurons after applying HRP to $A$, the posterior portion of the medial branch of the ventral ramus and $B$, the anterior portion of the medial branch of the ventral ramus. The muscles innervated by these branches are summarized in Table 1 . The conventions

groups (Fig. 1). Its posterior branch, the VRlp, innervates the intercostalis quadrangularis (iq) and the supracostalis lateralis superior (sls). The motoneurons filled from the VRlp were located in the ventral portion of the central part of the ventral horn (Fig. 7A). They were slightly ventral to the motoneurons filled from the VRma and were surrounded on the medial and ventral sides by motoneurons innervating epaxial muscles. The motoneurons were distributed near the ventral root, both rostral and caudal to it (Fig. 7A1).

A branch from the VRl innervates the levator costae muscle. A representative reconstruction of the levator costae motor pool is shown in Figure 7B. The most ventral motoneurons in the pool were located in the ventral part of the motor column, in a transverse position corresponding to the location of the longissimus and iliocostalis motor pools; however, levator costae motoneurons were consistently caudal to the labeled root (Fig. 7B1) and the longis- used in this figure are like those in Figure 5. Each bin in histogram A1 represents a longitudinal distance of $80 \mu \mathrm{m}$. Each bin in histogram B1 represents $120 \mu \mathrm{m}$.

simus and iliocostalis pools were rostral to it (Fig. 4B1,C1). These were the only motoneurons of a muscle innervated by the ventral ramus that were located in transverse positions usually occupied by motor pools of epaxial muscles. Other levator costae motoneurons were in more central regions in the ventral horn.

Summary of the motor pools. The motoneurons innervating axial muscles were located in the ventral part of the ventral horn. They were always near the root in which their axons exited from the cord; most were confined to roughly half of a segment rostral or caudal to it. Motor pools of individual muscles, or groups of muscles innervated by a common branch of a spinal nerve, were confined to reasonably discrete, characteristic locations in both the transverse and longitudinal extent of the motor column. Epaxial motor pools occupied the ventromedial part of the motor column and were spatially segregated from hypaxial 


\section{VRIP}
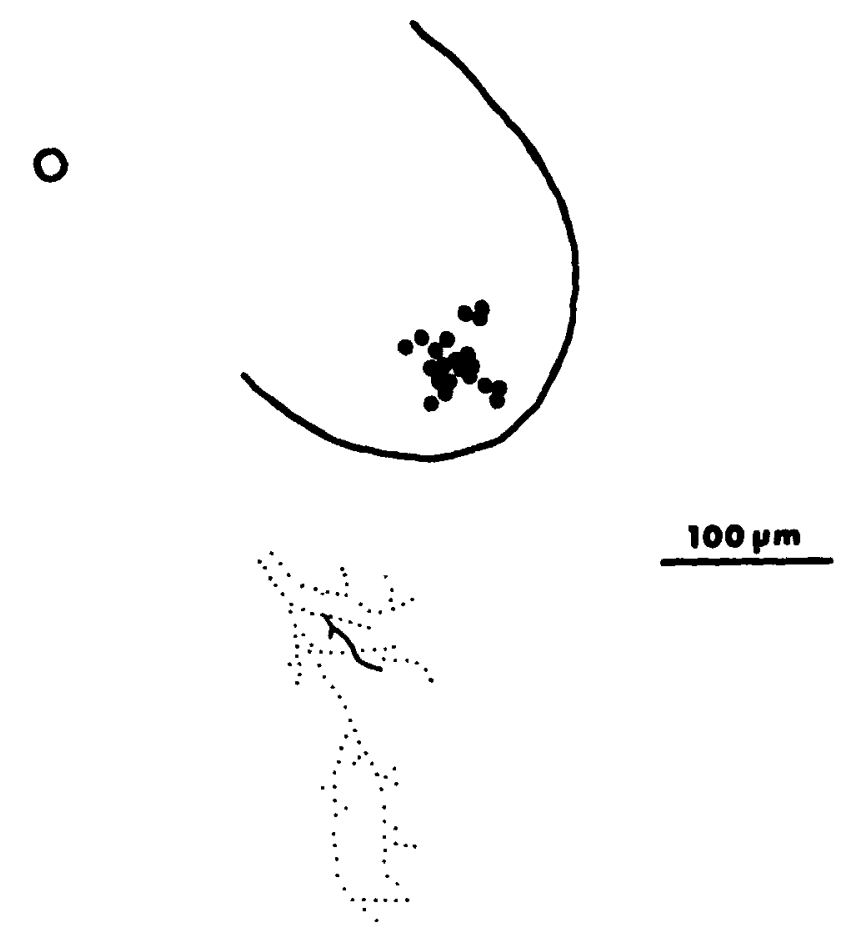

\section{LEVATOR COSTAE}
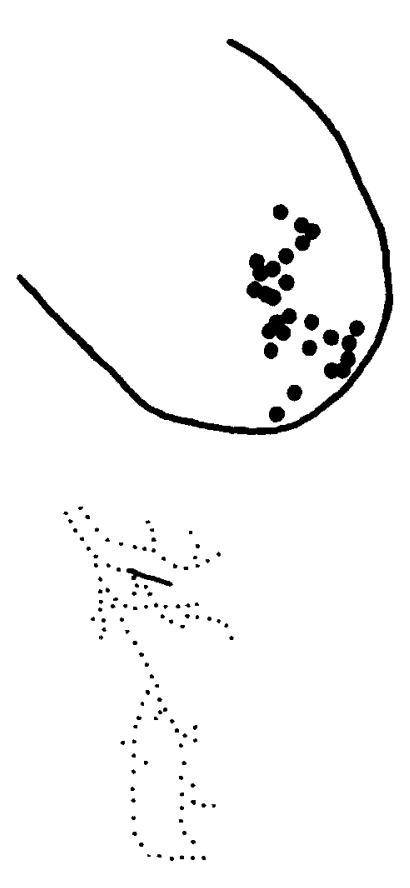

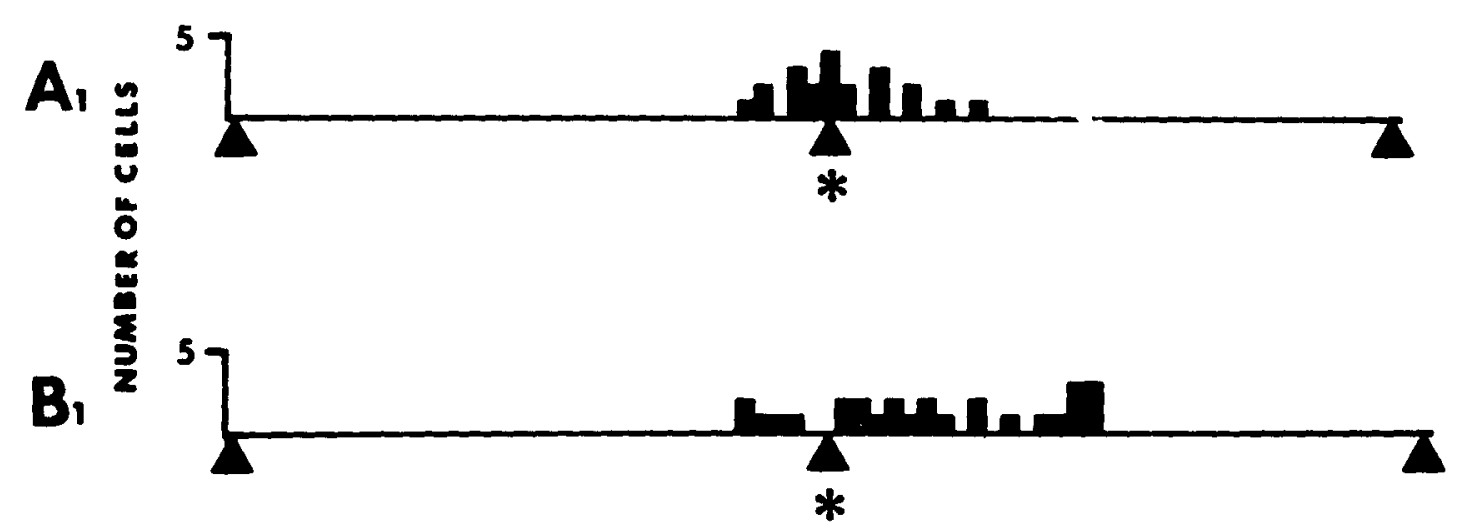

LONGITUDINAL DISTRIBUTION IN SPINAL CORD

rostrat

Fig. 7. The distribution of HRP-filled motoneurons after applying HRP to A, the posterior portion of the lateral branch of the ventral ramus and $B$, the nerve innervating the levator costae muscle. The conventions are like those in Figure 4. Each bin in both histograms represents a longitudinal distance of $120 \mu \mathrm{m}$.

pools that were dorsolateral. The only exception to this general rule was the motoneurons innervating the levator costae muscle. Some of these were located in the ventral part of the column like epaxial motoneurons, but they were segregated longitudinally from epaxial ones.

\section{Afferents}

In the course of mapping the motor pools of muscles, processes entering the spinal cord in the dorsal root were also filled with reaction product. I call these processes afferents below. Their organization warrants some attention in the context of this study because of the relationship observed between one population of afferents and the dendrites of motoneurons.

Two very discrete groups of afferents were filled whenever HRP was applied to a branch of a spinal nerve that innervated both muscles and skin. Figure 2A shows them in a transverse section through the region where they enter 
the cord. A dorsomedial group, indicated by the uppermost arrow, entered the cord above the dorsal horn, and a portion of these ramified in the dorsal part of the dorsal horn in regions roughly corresponding to laminae I, II, III, and IV identified by Kusuma and colleagues ('79) in Python. Fine branches of these processes within the dorsal horn are indicated by the upper arrow in the more highly magnified view shown in Figure $2 B$. These afferents, in this case filled from a branch of the ventral ramus, occupy the dorsomedial part of the dorsal horn; they are absent in the region ventrolateral to the tip of the upper arrow in Figure 2B. When HRP was applied to branches of the dorsal ramus of a spinal nerve, the labeled afferents in this dorsal group occupied the ventrolateral regions of the dorsal horn (not shown) not occupied by labeled afferents in Figure 2B. I conclude that the afferents in the dorsal and ventral rami project into different parts of the dorsal horn; the projection from the ventral ramus lies medial to the one from the dorsal ramus.

A ventrolateral bundle of afferents (lowermost solid arrow in Fig. 2A), which was always well separated from the dorsal group, extended deep into the cord to a region adjacent to the central gray matter. There, some processes from this bundle entered the central gray (laminae V and VI of Kusuma et al., '79) (Fig. 2B), and others ran ventrally along the lateral edge of the gray matter and intermingled with the dendritic processes of motoneurons (open arrows in Fig. 2A).

In transverse sections rostral or caudal to labeled dorsal roots the two groups of afferents were cut in cross section, as shown in Figure 2C. When these were traced in serial sections, they extended longitudinally, both rostrally and caudally, in the cord. Some processes exited from these bundles and entered the laminae occupied by afferents closer to the root. In summary, the two bundles of afferents ran longitudinally; processes exited from them and terminated in the dorsal and central gray in columns parallel to the bundles.

When nerves innervating only muscle (and not any skin) were exposed to HRP, HRP-filled afferents were only found in the ventrolateral group of afferents, as in Figure 2D. Therefore, muscle afferents travel only in the ventrolateral group.

\section{DISCUSSION Afferents}

Kusuma and colleagues (Kusuma, '79; Kusuma et al., '79) stained degenerating nerve fibers after transecting dorsal roots in Python and identified two distinct groups of afferents projecting to the dorsal and ventral portions of the cord. I have confirmed their observations in Nerodia with HRP and have in addition shown that muscle afferents travel only in the ventrolateral group.

Muscle and cutaneous afferents project to different regions of the gray matter in the spinal cord of some amphibians (Jhaveri and Frank, '83) and mammals (reviewed by Smith '83). In both, the cutaneous afferents project into the dorsal part of the dorsal horn, while muscle afferents project ventrally to regions near the dendrites or somata of motoneurons. My observations show a similar pattern in snakes. Muscles afferents travel only in a discrete bundle that projects ventrally and forms synaptic boutons in regions also occupied by the dendrites of motoneurons. Although there are no physiological studies of the connections of muscle afferents and motoneurons in snakes, the close anatomical association of the two suggests that muscle afferents form monosynaptic connections onto motoneurons.
Afferents entering the dorsal horn in Nerodia were only filled when nerves containing cutaneous branches were exposed to HRP. Therefore, it is likely that the afferents entering the dorsal horn are cutaneous afferents. I have not filled exclusively cutaneous nerves with HRP and therefore cannot rule out the possibility that some cutaneous afferents also project into the ventrolateral group.

In conclusion, afferents carrying different types of sensory information project to different regions in the spinal cords of reptiles as well as amphibians and mammals.

\section{Motor pools}

The few previous studies of the motoneurons innervating axial muscles in amniotes dealt with mammals (Richmond et al., '78; Brink et al., '79; Brichta and Peterson, '82; Smith and Hollyday, '83). Most of these were concerned only with neck muscles (Richmond et al., '78; Brichta and Peterson, '82) or with a small subset of the axial muscles (Brink et al., '79). The most comprehensive study in any amniote is a study of the thoracic motor pools in rats (Smith and Hollyday, '83). The organization of the motor pools of axial muscles in the Florida water snake is strikingly similar to their organization in rats; below, I compare the two.

The motor pools of different axial muscles in snakes and rats usually occupy separate, characteristic, locations in the ventral horn. Smith and Hollyday ('83) studied their distribution in the transverse but not the longitudinal extent of the motor column. However, they supposed that motor pools might also be segregated from one another longitudinally. I have confirmed their supposition. In snakes, the motor pools occupy characteristic locations in both the transverse and longitudinal extent of the motor column. In some cases (levator costae/longissimus-iliocostalis) motoneurons innervating different muscles occupied overlapping positions in the transverse extent of the motor column but were distributed differently along its rostrocaudal axis.

In both snakes and rats, epaxial motor pools are segregated from hypaxial ones. Epaxial pools are located ventromedially in the ventral horn, while hypaxial ones are dorsolateral (except for the levator costae motoneurons in snakes, discussed below). Sprague ('51) used chromatolysis to study the motoneurons projecting into the dorsal (epaxial) and ventral (hypaxial) rami of spinal nerves in rhesus monkeys. He found a similar segregation of motoneurons of dorsal and ventral rami in the lumbar and sacral regions, but they overlapped extensively in the thoracic region. However, even in thoracic areas the motoneurons projecting into the dorsal ramus were concentrated ventromedially in the column, and those projecting into the ventral ramus were largely dorsolateral. The overlap between the two was probably a result of the relatively poor resolution of the method of chromatolysis.

The three major groups of epaxial muscles are present in most reptiles and mammals, and in snakes and rats their motor pools occupy nearly identical locations in the ventral horn. In both, the motoneurons innervating the semispinalis-spinalis muscles are located along the ventromedial edge of the ventral horn, medial to the longissimus and iliocostalis motor pools, which occupy overlapping positions along its ventrolateral edge (Smith and Hollyday, '83).

Snakes have many more individual hypaxial muscles than rats, and the homologies of the muscles in the two groups are unclear. Nevertheless, there are some obvious similarities in the hypaxial motor pools in the two. The motor pools of the lateral (superficial) hypaxial muscles in snakes are located in the central portion of the ventral 
horn, like those of the superficial hypaxial muscles (external oblique, external intercostal) in rats. Gasc ('81) suggested that the lateral hypaxial muscles in snakes represented homologues of the external oblique and external intercostal muscles in other reptiles and mammals; the similarities in their motor pools are consistent with that conclusion. In rats, the motoneurons located in the extreme dorsolateral part of the motor column innervate hypaxial muscles on the medial side of the ribs (Smith and Hollyday, '83). I have not selectively filled motoneurons innervating medial hypaxial muscles in snakes. However, motoneurons in the dorsolateral part of the column were only filled when the branches of spinal nerves exposed to HRP innervated muscles in the group medial to the ribs. Therefore, it is likely that the motor pools of medial muscles also occupy comparable positions in rats and snakes.

The levator costae muscles in snakes and rats are morphologically similar, but in rats they are innervated by the dorsal ramus, while in snakes they are innervated by the ventral ramus. In spite of the difference in innervation some of the motoneurons of the levator costae muscle in snakes are located in the ventral portion of the ventral horn, like those in the levator costae pool of rats. These are the only motoneurons of a muscle innervated by the ventral ramus in snakes that were in the ventromedial part of the motor column, in a region that otherwise only contained dorsal ramus motoneurons. Other levator costae motoneurons are located in more dorsolateral positions, characteristic of other ventral ramus motoneurons. If the levator costae muscles in snakes and rats are homologous, as the similarities in their morphology and motor pools suggest, then the peripheral pathway taken by the axons innervating the muscles has changed.

Smith and Hollyday ('83) proposed that there is a topographic relationship between the position of motoneurons in the medial motor column, and the location, in embryonic life, of the axial muscles they innervate in the rat. Motoneurons innervating muscles derived from the dorsal part of the myotome are located ventromedially in the column, while motor pools of muscles derived from ventral myotome are located dorsolaterally. Furthermore, muscles derived from adjacent positions within the dorsal or ventral subdivisions of the myotome have motor pools in adjacent positions in the motor column. For example, semispinalisspinalis motor pools are next to longissimus and iliocostalis pools, and these muscles are derived from adjacent positions in the dorsal myotome. The embryonic origins of axial muscles in snakes are unknown, but the remarkable similarities in the motor pools of presumed homologous muscles in adult snakes and rats suggest that there is a topographic relationship between motoneurons and muscle during development in snakes that is very similar to the relationship present in rats.

The similarities in the motor pools of a terrestrial amniotic vertebrate with limbs (rat) and a limbless semiaquatic amniote (Florida water snake) are especially interesting because of what they imply about the evolution of the motor systems among amniotes. Snakes and rats move in very different ways. Snakes must rely exclusively upon axial muscles for locomotion, and they have developed a variety of kinematically different forms of locomotion, most of which depend on large lateral undulations of the body (Gray, '68). In contrast, the limbs play a primary role in the locomotion of rats (Cohen and Gans, '75); axial muscles are involved, but only secondarily so. There are differences in the details of the arrangement of axial muscles in the two animals (Gasc, '81), and they are probably in part a reflection of the differing roles of the muscles in locomotion. However, even though the details of the arrangements of muscles differ, and the roles of the muscles in locomotion are likely to be very different, the arrangements of the motor pools in the two animals are strikingly similar. The central and peripheral changes in the motor systems that underly the differences in the locomotor mechanics in the two seem to have occurred without any concomitant extensive reorganization of the motor pools (see Graf and Baker ('85) for a similar argument dealing with the oculomotor system of flounders).

Although the similarities in the motor columns of snakes and rats may reflect a reasonably conservative evolution of the medial motor column among amniotes, there is some evidence for a rather substantial reorganization of the motor column during the evolution of vertebrates. The medial motor columns in snakes and rats differ substantially from the motor columns in those anamniotic vertebrates that have been studied (van Raamsdonk et al., '83; Fetcho, '86). In most anamniotes, the axial musculature of adults retains the primitive myomeric structure evident only in the embryos of amniotes. However, there is little evidence in the adult of the topographic relationship between motoneurons and muscle one would expect if their motor columns were organized like those in rats and snakes. The motoneurons innervating epaxial muscle are not segregated from those innervating hypaxial muscle; there is no simple relationship between the position of a motoneuron in the motor column and the position of the muscle it innervates in the dorsoventral extent of the myomeres. Instead, features of the organization of the motor column are related to the functional subdivision of their myomeres into superficial red and deep white portions (van Raamsdonk et al., '83; Fetcho, '86). These two very different arrangements of mo toneurons in different vertebrates require a major evolutionary reorganization of the motor column. This reorganization seems to have accompanied the more extensive anatomical and functional differentiation of the myotomal musculature in the amniotes and may have been important for the central control of the many individual muscles arising from the myotomes.

\section{ACKNOWLEDGMENTS}

I thank Dr. Stephen S. Easter, Jr., for his advice throughout the course of this work, and for his thorough comments on the manuscript. I also thank Drs. R. Glenn Northcutt, Bruce Oakley, Pamela Raymond, and Steven Scherer for their comments on early versions of the manuscript. David Bay helped with the photography. Financial support was provided in part by an NSF predoctoral fellowship, by the Division of Biological Sciences at the University of Michi gan, and by NIH grant EY00168 to Dr. S.S. Easter, Jr. This work was submitted in partial fulfillment of the requirements for the Ph.D. in Biological Sciences at the University of Michigan.

\section{LITERATURE CITED}

Auffenberg, W. (1961) Additional remarks on the evolution of trunk musculature in snakes. Am. Mid. Natl. 65:1-16.

Auffenberg, W. (1962) A review of the trunk musculature in the limbless land vertebrates. Am. Zool. 2:183-190.

Brichta, A., and E.H. Peterson (1982) Organization of motor pools supplying cervical musculature in the rat. Soc. Neurosei. Abstr. 8:876.

Brink, E.E., J.I. Morrell, and D.W. Pfaff (1979) Localization of lumbar epaxial moto-neurons in the rat. Brain Res. 170:23-41. 
Cohen, A.H., and C. Gans (1975) Muscle activity in rat locomotion: Movement analysis and electromyography of the flexors and extensors of the elbow. J. Morphol. 146:177-196.

Fetcho, J.R. (1986) The organization of the motoneurons innervating the axial musculature of vertebrates: I. Goldfish (Carassius auratus and mudpuppies (Necturus maculosus). J. Comp. Neurol. 249:521-550.

Gasc, J.P. (1981) Axial musculature. In C. Gans and T.S. Parsons (eds): Biology of the Reptilia Vol. 11. New York: Academic Press, pp. 355-435.

Graf, W., and R. Baker (1985) The vestibuloocular reflex of the adult flatfish. I. Oculomotor organization. J. Neurophysiol. 54:887-899.

Gray, J. (1968) Animal Locomotion. London: Weidenfeld and Nicolson.

Jayne, B. (1982) Comparative morphology of the semispinalis-spinalis muscle of snakes and correlations with locomotion and constriction. J. Morphol. 172:83-96.

Jhaveri, S., and E. Frank (1983) Central projections of the brachial nerve in bullfrogs: Muscie and cutaneous afferents project to different regions of the spinal cord. J. Comp. Neurol. 221:304-312.

Kusuma, A. (1979) The Organization of the Spinal Cord in Reptiles With Different Locomotor Patterns. Ph.D. dissertation. Nijmegen 152pp.

Kusuma, A., H.J. ten Donkelaar, and R. Nieuwenhuys (1979) Intrinsic organization of the spinal cord. In. C. Gans, R.G. Northcutt, and P. Ulinski (eds): Biology of the Reptilia. Vol. 10. New York: Academic Press, pp. 59-109.

Lichtman, J.W., R.S. Wilkinson, and M.M. Rich (1985) Multiple innervation of tonic endplates revealed by activity-dependent uptake of fluorescent probes. Nature 314:357-359.

Mosauer, W. (1935) The myology of the trunk region of snakes and its significance for ophidian taxonomy and phylogeny. Publ. Univ. Calif Los Angeles 1:81-120.
Nishi, S. (1938) Muskeln des Rumfes. In L. Bolk, E. Göppert, E. Kallius, and W. Lubosch (eds): Handbuch der vergleichenden Anatomie der Wirbeltierre. Berlin und Wien: Urban \& Schwarzenberg, pp. 351-446.

Northcutt, R.G. (1979) The comparative anatomy of the nervous system and the sense organs. In. M.H. Wake (ed): Hyman's Comparative Vertebrate Anatomy. Chicago: University of Chicago Press, pp. 615-769.

Raamsdonk, W. van, W. Mos, M.J. Smit-Onel, W.J. van der laarse, and R. Fehres. (1983) The development of the spinal motor column in relation to the myotomal muscle fibers in the Zebrafish (Brachydanio rerio) I. Posthatching development. Anat. Embryol. 167:125-139.

Richmond, F.J., D.A. Scott, and V.C. Abrahams (1978) Distribution of motoneurons to neck muscles, biventer cervicis, splenius and complexus in cat. J. Comp. Neurol. 181:451-463.

Ridge, R.M.A.P. (1971) Different types of extrafusal muscle fibers in snake costocutaneous muscles. J. Physiol. (Lond.) 217:393-418.

Romer, A.S., and T.S. Parsons (1977) The Vertebrate Body. Philadelphia: W.B. Saunders.

Smith, C.L. (1983) The development and postnatal organization of primary afferent projections to the rat thoracic spinal cord. J. Comp. Neurol. 220:29-43.

Smith, C.L., and M. Hollyday (1983) The development and postnatal organization of motor nuclei in the rat thoracic spinal cord. J. Comp. Neurol. 220:16-28.

Sprague, J.M. (1951) Motor and propriospinal cells in the thoracic and lumbar ventral horn of the rhesus monkey. J. Comp. Neurol. 95:105123.

Wright, A.H., and A.A. Wright (1957) Handbook of Snakes of the United States and Canada. Vol. 1. Ithaca, N.Y.: Comstock Pub. Assoc 